\title{
Badge Size Reflects Sperm Oxidative Status within Social Groups in the House Sparrow Passer domesticus
}

\author{
Alfonso Rojas Mora ${ }^{1}$, Magali Meniri ${ }^{1}$, Gaëtan Glauser $^{2}$, Armelle Vallat ${ }^{2}$ and \\ Fabrice Helfenstein $^{1 *}$ \\ 1 Laboratory of Evolutionary Ecophysiology, Institute of Biology, Faculty of Sciences, University of Neuchâtel, Neuchâtel, \\ Switzerland, ${ }^{2}$ Neuchâtel Platform for Analytical Chemistry NPAC, Institute of Chemistry, Faculty of Sciences, University of \\ Neuchâtel, Neuchâtel, Switzerland
}

\section{OPEN ACCESS}

Edited by:

François Criscuolo,

Centre National de la Recherche Scientifique, France

Reviewed by: Jose Carlos Noguera, University of Glasgow, UK Josefa Bleu, Université Pierre et Marie Curie, France

${ }^{*}$ Correspondence:

Fabrice Helfenstein fabrice.helfenstein@free.fr

Specialty section:

This article was submitted to Behavioral and Evolutionary Ecology, a section of the journal Frontiers in Ecology and Evolution

Received: 28 February 2016 Accepted: 27 May 2016

Published: 09 June 2016

Citation:

Rojas Mora A, Meniri M, Glauser G, Vallat $A$ and Helfenstein $F$ (2016) Badge Size Reflects Sperm Oxidative Status within Social Groups in the House Sparrow Passer domesticus. Front. Ecol. Evol. 4:67. doi: 10.3389/fevo.2016.00067
The phenotype-linked fertility hypothesis proposes that male ornaments reflect male fertility. Male ornaments could honestly signal sperm quality due to the high susceptibility of sperm to free radicals on the one hand and the negative impact of oxidative stress on ornament elaboration on the other hand. Thus, only males with superior antioxidant defenses could bear the cost of more elaborated sexual ornaments without suffering adverse fitness costs. Yet, in species where males experience differential access to fertile females, a trade-off emerges between investing into traits favoring mating opportunities (e.g., secondary sexual ornaments, social dominance, mate-guarding behaviors, etc.) or into traits favoring sperm competitive ability (e.g., sperm numbers and quality). When male sexual ornaments promote greater access to fertile females, a negative relationship can then be predicted between ornamentation and sperm quality. We tested the latter hypothesis and the phenotype-linked fertility hypothesis in wild House Sparrows Passer domesticus by exploring the relationships between sperm quality, melanin-based ornamentation, and redox status in blood and sperm. We found no correlation between badge size and sperm swimming performance. However, we found that within a social group, large-badged males better protect their ejaculates from oxidative stress, and thus produce less oxidized ejaculates. Additionally, we found that badge size did not reflect social dominance, and thus the protection of the ejaculate is independent of males' ability to monopolize resources. Our results suggest that badge size might reflect male investment into the antioxidant protection of their sperm relative to a given social environment, and thus females may accrue both direct and indirect benefits by mating with large-badged males producing less oxidized ejaculates.

\footnotetext{
Keywords: oxidative stress, phenotype-linked fertility, sperm competition, soma vs. germline, melanin-based ornaments
}

\section{INTRODUCTION}

Oxidative stress is the imbalance between pro- and anti-oxidants in favor of the former (Jones, 2006). Oxidative stress is pervasive in an animal's life because virtually all activities generate prooxidant reactive oxygen species (ROS), and, although all living forms have evolved antioxidant defenses, the latter may fail to quench ROS before they cause damage (Benzie, 2000; Jones, 2006; Halliwell and Gutteridge, 2007). While ROS are necessary for various physiological processes 
(Finkel and Holbrook, 2000), an excess of ROS has dramatic physiological consequences given that ROS cause oxidative damage to all biological molecules (proteins, lipids, carbohydrates and DNA) (Halliwell and Gutteridge, 2007), and thus oxidative stress has been identified as a cost of reproduction (Wang et al., 2001; Alonso-Alvarez et al., 2004) and immunity (inflammation; Sorci and Faivre, 2009), as well as a proximate mechanism of senescence and aging (Harman, 1956; Salmon et al., 2010). Hence, individual ability to circumvent oxidative stress may underlie trade-offs between life-history traits (Costantini, 2008; Monaghan et al., 2009; Metcalfe and Alonso-Alvarez, 2010).

Vertebrate spermatozoa are very susceptible to oxidative stress (Tremellen, 2008), and oxidative damage to sperm is known to reduce sperm quality (Surai et al., 2001; Aitken and Baker, 2004; Helfenstein et al., 2010). For instance, oxidative damage to sperm can have a series of negative effects on male and potentially female fitness, due to various degrees of male infertility ranging from reduced sperm mobility or impaired sperm-egg interaction, to lower offspring quality due to oxidation-induced heritable deleterious mutations to sperm DNA (Velando et al., 2008). Additionally, sperm quality is a key parameter in sperm competition, the circumstance when ejaculates of different males compete to fertilize a common set of ova (Parker, 1970; Birkhead et al., 1999; Gage et al., 2004; Denk et al., 2005). Therefore, oxidative stress may play a pivotal role in species where males face such competition. Oxidative stress may affect life-history strategies and the resolution of trade-offs such as investing in the antioxidant protection of somatic functions or in the antioxidant protection of gametes (Dowling and Simmons, 2009; Parker et al., 2013). As a consequence, males' intrinsic antioxidant capacity could determine to what extend they can protect sperm from oxidative stress, which in turns will affect their reproductive strategies (e.g., territorial, mate-guarding strategies aiming at reducing sperm competition vs. copulation-sneaking strategies unavoidably facing sperm competition) (Dowling and Simmons, 2009).

The phenotype-linked fertility hypothesis states that male ornaments signal sperm quality and fertilizing efficiency (Sheldon, 1994). Therefore, females choosing to copulate with more ornamented males would accrue direct fitness benefits through fertility insurance (Sheldon, 1994). Further, females mating with highly ornamented males can also acquire indirect fitness benefits through the production of better quality offspring (Velando et al., 2008) and/or attractive sons with superior fertilizing efficiency and sperm competitive ability (i.e., the sexy sperm hypothesis) (Keller and Reeve, 1995; Yasui, 1997). Male ornaments have been proposed to reflect male antioxidant capacity (Von Schantz et al., 1999), and oxidative stress may therefore mediate the link between secondary sexual characters and sperm quality (Blount et al., 2001; Velando et al., 2008). Evidence exists that carotenoid-based colorful ornaments reflect a male's ability to protect his sperm from oxidative stress, and thus may signal sperm quality and fertilizing efficiency (Helfenstein et al., 2010; Pike et al., 2010). It has recently been suggested that melanin-based ornaments, and particularly eumelanin-based colored integuments, positively reflect resistance to oxidative stress (McGraw, 2005; Ducrest et al., 2008; Galván and Alonso-Alvarez, 2008, 2009). Such traits would thus have the potential to signal antioxidant protection to sperm and sperm quality, an untested hypothesis so far.

Theoretical models of sperm competition predict that males having reduced access to females such as sub-dominant, lowranking males, should be selected to invest less in somatic functions involved in acquisition of matings (e.g., secondary sexual characters, mate-guarding, male-male competitive ability) and more in sperm traits (e.g., percentage of motile sperm, sperm swimming ability) that confer greater fertilizing efficiency to compensate for a lower number of mating opportunities (Parker, 1998; Tazzyman et al., 2009; Parker and Pizzari, 2010; Parker et al., 2013). Conversely, more attractive males with privileged access to females should be selected to invest more into somatic functions and less into their germline. In species where male ornaments predict male's ability to monopolize fertile females, this soma/germline allocation trade-off hypothesis predicts a negative correlation between the degree of elaboration of an ornament and sperm quality. This hypothesis has been substantiated in fish and bird species where more ornamented, territorial, or dominant males, who can monopolize females and hence face a reduced risk of sperm competition, produce sperm of lower quality than males in disfavored roles (Vladic and Järvi, 2001; Froman et al., 2002; Neff et al., 2003; Gage et al., 2004; Rudolfsen et al., 2006; Cornwallis and Birkhead, 2007; Pizzari et al., 2007). Since both somatic functions and sperm cells likely suffer from the deleterious effects of ROS, hence requiring a tight control of the redox balance via an efficient antioxidant system, it can be hypothesized that males may face a trade-off in the allocation of antioxidant resources to either the antioxidant protection of somatic functions or the antioxidant protection of their germline. Oxidative stress and antioxidant capacity would thus mediate the soma/germline allocation trade-off. Under such hypothesis more ornamented males should invest less antioxidant in their testes and semen for the protection of their sperm, leading to lower sperm quality, and more antioxidants to the rest of their body for the protection of their soma, and vice-versa for less ornamented males.

The oxidation-based developments of the phenotype-linked fertility hypothesis and the soma/germline allocation trade-off hypothesis are not mutually exclusive. If more ornamented males have higher overall antioxidant capacity, they may be able to invest into the antioxidant protection of both their soma and sperm. Males of higher quality may thus have more elaborated sexual ornaments, greater access to females and more mating opportunities, and still produce higher quality sperm. Lowquality, less ornamented males on the other hand, may be more constrained in this trade-off and thus have to sacrifice the antioxidant protection of their soma to the benefit of their sperm to increase their sperm competitive ability. Combining both the predictions of the oxidation based phenotype-linked fertility hypothesis and sperm competition models generates the expectation of a non-linear, U-shaped, relationship between the degree of elaboration of an ornament and sperm quality, where both the most ornamented males and the least ornamented males would produce high quality sperm. 
House sparrows Passer domesticus are socially monogamous passerine birds exhibiting significant levels of sperm competition and extrapair paternity (12-15\%) resulting from female promiscuity and forced copulations (Møller, 1987; Wetton and Parkin, 1991; Møller and Birkhead, 1994; Birkhead et al., 1995; Wetton et al., 1995). Additionally, males exhibit a badge of black melanin-colored feathers on their breast. This black badge is known to be associated with social dominance (Nakagawa et al., 2007), and dominance in turn is positively related to sexual displays and copulation rates (Riters et al., 2004). Yet, although some studies found a positive relationship between badge size and reproductive success (Møller, 1988, 1990), others failed to do so (See references in Nakagawa et al., 2007). Further, a non-linear relationship was found in an Austrian population between badge size and paternity losses (Václav et al., 2002). It thus appeared to us that the non-linear relationship between badge size and paternity losses could be the result of a complex non-linear relationship between badge size and sperm quality, which in turn may potentially be modulated by the acquisition and allocation of antioxidant resources. In the present study, we tested in wild-caught House Sparrows the predictions of such non-linear relationships between ejaculate quality, ejaculate redox status, and badge size.

\section{MATERIALS AND METHODS}

\section{Individuals and Sampling}

We trapped a total of 60 male and 60 female house sparrows using mist-nets in western Switzerland in April 2014. We measured body mass and tarsus length prior to housing the birds in 15 mixed outdoor aviaries (four males and four females per aviary) at the Ethological Station, University of Bern, Switzerland. After 4 weeks of acclimation all the females were transferred into a separate aviary, and we took a blood and a sperm sample from all males. We then collected a second sperm sample the day after, and a third sperm sample $48 \mathrm{~h}$ after the second. This procedure ensured that, as copulation rates likely varied across males of different social ranks, any differences in sperm characteristics would be intrinsic differences in quality rather than differences due to depletion (Preston et al., 2001) or fresh sperm effects (SivaJothy, 2000; Pizzari et al., 2008). Males were divided in three sampling groups of 5 aviaries, and groups were processed 5 days apart.

To establish the hierarchy of the males in each aviary, we recorded a total of $13 \mathrm{~h}$ of observations in each aviary. We removed the feeders for $1.5 \mathrm{~h}$, and then recorded all the antagonistic interactions at the feeders for $1 \mathrm{~h}$ after reintroducing the feeders into the aviaries. Within each aviary, we computed each male's David's score as a proxy for their social rank (Gammell et al., 2003).

\section{Ejaculate Quality}

Ejaculates were collected in glass capillaries after massaging male's cloaca, and $0.25 \mu \mathrm{L}$ of ejaculate were immediately diluted in $40 \mu \mathrm{L}$ of preheated Dulbecco Modified Eagle Medium at $40^{\circ} \mathrm{C}$. Then the diluted ejaculated was loaded into a $20 \mu \mathrm{m}$-deep chamber (Leja, Netherlands) and a video of the moving sperm was recorded using a Toshiba CMOS HD camera (TOSHIBA Corporation, Japan) mounted on an Olympus BX43 microscope (Olympus Co., Japan) at 100X magnification and phase contrast 3 annular ring. A subsample of the ejaculate was diluted in PBS and stored at $-80^{\circ} \mathrm{C}$ for laboratory analyses. From the videos we estimated standard ejaculate quality traits using a Computer Assisted Sperm Analyser plug-in (Wilson-Leedy and Ingermann, 2007) for ImageJ (Schneider et al., 2012). Specifically, the Computer Assisted Sperm Analyser calculates the proportion of motile sperm, curvilinear velocity (e.g., the total distance traced by an spermatozoon; VCL), straight line velocity (e.g. the straight distance between the initial and the final point traveled by a spermatozoon; VSL), average path velocity (e.g., a smooth trajectory of the total traveled distance; VAP), and linearity (e.g., the ratio between the straight line and the total traveled distance). Several studies have analyzed those sperm traits either separately (e.g., Gage et al., 2004; Rudolfsen et al., 2006) or together in a single multivariate analysis (e.g., Malo et al., 2005; Helfenstein et al., 2010), yet the speed measurements are highly correlated in our dataset (all pairwise $r_{\text {spearson }}>0.98$ ). Furthermore, VCL and proportion of motile sperm have been found to be major determinants of the outcome of sperm competition (e.g., Froman et al., 1999; Gage et al., 2004; Malo et al., 2005). We therefore kept these two traits as measures of ejaculate quality. Finally, we modeled the rate at which initial speed decreases through time, referred as ejaculate longevity), as well as the rate at which initial proportion of swimming sperm decreases through time, referred as swimming endurance, using mixed linear models with time as a fixed effect and individual identity as a random slope and intercept.

\section{Oxidative Stress and Antioxidant Defenses}

Antioxidant defenses and an individual's redox balance are characterized by a multidimensional system integrating several lines of antioxidant defenses and oxidative damage to various biomolecules (Cohen and McGraw, 2009; Monaghan et al., 2009). Thus, and as advocated by Hõrak and Cohen (2010), we chose to describe individual redox status through (1) a specific marker of oxidative damage, i.e., the levels of end-products of lipid peroxidation, (2) a marker of cellular oxidative stress, i.e., the ratio of oxidized over reduced glutathione, and (3) the activity of the antioxidant enzyme SOD, i.e., an endogenous antioxidant that catalyzes the dismutation of superoxide anions into molecular oxygen or hydrogen peroxide. We assessed these markers in two somatic tissues, i.e., the plasma and the red blood cells, and in a tissue of the germline function, i.e., the ejaculate.

Malondialdehyde (MDA) is an end-product of lipid peroxidation that provides a good measurement on the amount of lipid damage due to ROS attack (Halliwell and Gutteridge, 2007; Monaghan et al., 2009), and thus we determined the levels of MDA in plasma, erythrocytes, and sperm. Concentrations of MDA, formed by the $\beta$-scission of peroxidised fatty acids, were assessed using UHPLC with fluorescence detection, following Moselhy et al. (2013) and Agarwal and Chase (2002) with modifications. All chemicals were of analytical or HPLC grade, and chemical solutions were prepared using ultrapure water (Milli-Q Synthesis; Millipore Corporation, Billerica, MA, USA). 
To a (plasma or RBC / sperm) 5/8 $\mu$ l aliquot of sample $(0.8 \mu \mathrm{L}$ of sperm in $7.2 \mu \mathrm{L}$ of PBS; $0.5 \mu \mathrm{L}$ of erythrocytes in $4.5 \mu \mathrm{L}$ of PBS; $5 \mu \mathrm{L}$ of plasma) or standard (1,1,3,3-tetraethoxypropane, TEP; Sigma Aldrich, USA), 155/152 $\mu \mathrm{l}$ of water, $40 \mu \mathrm{l}$ of trichloroacetic acid 5\% (TCA), and $20 \mu \mathrm{l}$ thiobarbituric acid (TBA; Sigma Aldrich, USA) solution (42 mM) were added in a $1.5 \mathrm{~mL}$ tube. Samples were then vortex mixed for $5 \mathrm{~s}$ and centrifuged for $14 \mathrm{~min}$ at $14,000 \mathrm{rpm}$ and $4^{\circ} \mathrm{C}$. $205 \mu \mathrm{L}$ of the epiphase was transferred to $2 \mathrm{ml}$ capacity conical-bottom screwtop microcentrifuge tubes, vortex mixed for $5 \mathrm{~s}$, then heated at $100^{\circ} \mathrm{C}$ for exactly $1 \mathrm{~h}$ in a dry bath incubator to allow formation of MDA-(TBA) 2 adducts. Samples were then cooled on ice for 5 min, and $150 \mu \mathrm{L}$ of butanol (Sigma Aldrich, USA) were added. Then, the tubes were vortex mixed for $10 \mathrm{~s}$ and centrifuged for $10 \mathrm{~min}$ at $14,000 \mathrm{rpm}$ and $4^{\circ} \mathrm{C}$. Then, $120 \mu \mathrm{L}$ of the epiphase was recovered in $1.5 \mathrm{~mL}$ tubes. A second extraction of the derivatised solution was done by adding $150 \mu \mathrm{L}$ of butanol, vortex mixed for $10 \mathrm{~s}$ and centrifuged for $10 \mathrm{~min}$ at $14,000 \mathrm{rpm}$ and $4^{\circ} \mathrm{C}$. Then, $140 \mu \mathrm{L}$ of the epiphase was pooled with the previously recovered epiphase, and then evaporated in a SpeedVac for $60 \mathrm{~min}$ at $35^{\circ} \mathrm{C}$. Finally, the product was re-suspended in $90 \mu \mathrm{L}$ of methanol $30 \%$ (Sigma Aldrich, USA), and the tubes were sonicated for $5 \mathrm{~s}$ and then vortex mixed for $10 \mathrm{~s}$. A $70 \mu \mathrm{l}$ aliquot was collected and transferred to an HPLC vial for analysis. Samples $(5 \mu \mathrm{l})$ were injected into a Dionex Ultimate 3000 Rapid Separation LC system (Dionex Corporation, California, USA) fitted with a Waters (Milford Massachusetts, USA) Acquity UPLC ${ }^{\circledR}$ BEH C18 column $(1.7 \mu \mathrm{m}, 2.1 \times 50 \mathrm{~mm})$ maintained at $30^{\circ} \mathrm{C}$. Separation was achieved using gradient elution at a flow rate of $0.4 \mathrm{ml} / \mathrm{min}$ with solvent A being $0.05 \%$ acetic acid buffered at $\mathrm{pH} 6$ with ammonium hydroxide and solvent $\mathrm{B}$ acetonitrile. The gradient was as follows: linear increase from 5 to $100 \%$ solvent B over 5 min, followed by $100 \%$ solvent B for $1.5 \mathrm{~min}$ and re-equilibration at initial conditions (5\% B) for $3.2 \mathrm{~min}$. The total analysis time was $9.7 \mathrm{~min}$. The auto-sampler syringe was washed with $700 \mu \mathrm{l}$ of solvent B after each injection. Data were acquired using a fluorescence detector set at $515 \mathrm{~nm}$ (excitation) and $553 \mathrm{~nm}$ (emission). For calibration, a standard curve was prepared using a TEP stock solution (5 $\mu \mathrm{M}$ in $40 \%$ ethanol) serially diluted using pure water. Standards were run in duplicates, and were highly repeatable (linear mixed model, intra-class correlation coefficient, $r=0.99$; Nakagawa and Schielzeth, 2010). The repeatability of plasma samples was estimated in the same species, but from another dataset, and was equally high, $r=0.90$.

Glutathione in its reduced form (GSH) is an endogenous intra-cellular tri-peptide that can quench ROS in a reaction catalyzed by the enzyme glutathione peroxidase, thus being oxidized into glutathione disulphide (GSSG) (Halliwell and Gutteridge, 2007). Hence, the proportion of oxidized glutathione over total glutathione (GSSG/tGSH) is used as an accurate measurement of the oxidative balance of cells (Cnubben et al., 2001). We determined the levels of glutathione in both its reduced and oxidized forms both in sperm and red blood cells using UHPLC-MS/MS (adapted from Bouligand et al., 2006). We mixed (sperm/RBC) $3 / 10 \mu \mathrm{L}$ of aliquot $(0.3 \mu \mathrm{L}$ sperm in $2.7 \mu \mathrm{L}$ of PBS; $1 \mu \mathrm{L}$ of erythrocytes in $9 \mu \mathrm{L}$ of PBS), 5/25 $\mu \mathrm{L}$ of TCA $5 \%, 5 \mu \mathrm{L}$ of glutathione ethyl ester (GSHee; Sigma Aldrich, USA) as internal standard $(2.25 \mu \mathrm{g} / \mathrm{mL}$ or $20 \mu \mathrm{g} / \mathrm{mL}$ respectively), and $62 / 0 \mu \mathrm{L}$ of pure water in a $1.5 \mathrm{~mL}$ tube. Then, the solutions were vortex mixed, kept ice-cold for $5 \mathrm{~min}$, and centrifuged for $14 \mathrm{~min}$ at $140,000 \mathrm{rpm}$ and $4^{\circ} \mathrm{C}$. After centrifugation, $50 / 20 \mu \mathrm{L}$ of the epiphase were diluted in $100 / 980 \mu \mathrm{L}$ of water and then $100 \mu \mathrm{L}$ of the dilution was transferred into glass HPLC vials. Samples $(5 \mu \mathrm{l})$ were injected on a Dionex Ultimate 3000 Rapid Separation LC system (Dionex Corporation, California, USA) coupled to a 4000 QTRAP mass spectrometer (Sciex, Toronto, Canada) equipped with a Turbo V source. A Waters Acquity UPLC ${ }^{\circledR}$ BEH HSS T3 column $(1.8 \mu \mathrm{m}, 2.1 \times 100 \mathrm{~mm})$ was employed at a flow rate of $0.4 \mathrm{ml} / \mathrm{min}$ using the following solvent system: solvent $\mathrm{A}=$ milliQ $\mathrm{H}_{2} \mathrm{O}$ with $0.05 \%$ formic acid, solvent $\mathrm{B}=$ acetonitrile with $0.05 \%$ formic acid. The gradient was as follows: $0-20 \% \mathrm{~B}$ in $2 \mathrm{~min}$, $20-100 \%$ B in $3 \mathrm{~min}, 100 \%$ B for $3 \mathrm{~min}$, back to $0 \%$ B for $5 \mathrm{~min}$. Total analysis time was $13 \mathrm{~min}$. Mass spectrometry detection was achieved using multiple reaction monitoring (MRM) transitions in positive ionization mode. A dwell time of $50 \mathrm{~ms}$ was applied for all transitions. Ion source parameters were as follows: capillary voltage $5.5 \mathrm{kV}$, nebulizing gas (GS1) 45 psi, drying gas (GS2) 25 psi at $550^{\circ} \mathrm{C}$, curtain gas (CUR) 15 psi. For quantification, a standard curve containing GSH (Sigma Aldrich, USA) and GSSG (Sigma Aldrich, USA) at $0.002,0.02,0.1,0.5$, and $2 \mu \mathrm{g} / \mathrm{mL}$ and GSHee at a constant concentration of $0.05 \mu \mathrm{g} / \mathrm{mL}$ was made. Repeatability was assessed using standards from different HPLC runs, and was high for both GSH and GSSG, $r=0.976$ and $r=0.945$ respectively.

Superoxide dismutase is an endogenous enzymatic antioxidant that catalyzes dismutation of superoxide anions into molecular oxygen or hydrogen peroxide (Halliwell and Gutteridge, 2007). Thus, we also measured superoxide dismutase activity per $\mathrm{ml}$ of tissue in sperm and blood applying minor modifications to a commercial kit (Cayman Chemical, USA). Specifically, with used dilution of 1:400 for erythrocytes and 1:160 for sperm. All the samples were assayed in duplicates yielding low intra-plates CVs (: $10.7 \%$ for sperm and $9.9 \%$ for erythrocytes). Additionally, the inter-plate repeatability was assessed using 23 erythrocyte and 50 sperm samples, and was found to be high for both tissues: $r=0.89$ and $r=0.85$, respectively.

\section{Badge Size}

From each individual we took two independent photos in a dorsal position by holding the bird tarsi and gently pushing down the beak. A millimeter paper was placed bellow the bird, and all the photos were taken at the same focal distance and light conditions. House sparrows make a single molt every year during fall, during males grow a black eumelanin-based badge of feathers on their breast. The feathers on the edge of this badge have light brown apex, which partially mask the underlying black feathers (Ginn and Melville, 1983). These light brown apexes wear off during the season, thus fully revealing the male's badge (Møller and Erritzøe, 1992). The extent to which the light brow apexes wear off can be behaviorally controlled, and males with larger badges preen and dust bath more than small badged males (Møller and Erritzøe, 1992). Thus, while the exposed part of their badge will reflect their ability to compete with other males, the total size of their 
badge (i.e., including the covered edges) will reflect their gross investment into ornament production (Hill and McGraw, 2006). We used Adobe Photoshop CS5 to measure the badge size using a lasso tool to select the area where the badge is, avoiding the beak and face mask that have also a black coloration. Then, we used the color range tool to select the black areas of the badge set to $70 \%$ of tolerance (hereafter referred as exposed badge). This tolerance value was set arbitrarily based on visual inspection and in a way that optimized the selection of the badge pixels. Finally, we used the quick selection tool to manually select the unexposed parts of the badge that were not selected by the automated selection (hereafter referred as total badge). All photos were measured twice blindly from the previous measurements. The within-photo repeatability was $r=0.96$, and the between-photo (within the same male) was $r=0.72$.

\section{Statistical Analyses \\ Badge Size and Social Dominance}

Several studies have argued that badge size reflects the dominance status of a male (reviewed in Nakagawa et al., 2007). Thus, we tested whether within the social groups badge size would reflect the social rank predicted by the David's score (Gammell et al., 2003). We performed two linear mixed models that included social rank as the response variable and either total or exposed badge size centered by the aviary means as the independent variable. Additionally, body mass and tarsus length were included as covariates, and both aviary and sampling date were used as random factors.

\section{Predictions of the Phenotype-Linked Fertility Hypothesis}

The PLFH predicts a positive relationship between the sexual signal and sperm quality across the whole population, the signal being an absolute indicator of male fertility. If male fertility and the sexual signal share a common susceptibility to male redox balance, we thus expect (1) a positive relationship between the sexual signal and sperm quality, and (2) negative relationships between the sexual signal on the one hand and the level of oxidative stress endured in the soma and the sperm on the other hand.

\section{Predictions of the Oxidation-Based Soma/Germline Allocation Trade-Off Hypothesis}

This hypothesis does not make predictions at the population level. It is based on differential access to fertile females by males with different sexual attractiveness within a given social group. Predictions must thus be drawn at the level of the social group within which males and females interact and within which males are assessed by the females. The oxidation-based soma/germline allocation trade-off hypothesis thus predicts that, within groups, (1) sexual signal and sperm quality should be either negatively related (simple allocation trade-off) or, if the most preferred males accrue more resources (e.g., the big house and big car effect; Reznick et al., 2000), follow a U-shaped relationship. There should also be (2) a negative or U-shaped relationship between the intensity of the sexual signal and the amount of antioxidant resources (SOD activity) invested in sperm, and (3) a positive or bell-shaped relationship between the sexual signal and the amount of oxidative damage (MDA) or level of oxidative stress (GSSG/tGSH) in sperm.

We used linear mixed models to test our hypotheses. We modeled both ejaculate traits and antioxidant resources as a function of either the total or exposed badge size, including body mass and tarsus length as covariates. We tested the PLFH using quadratic models with absolute badge size as the explanatory variable. We tested the soma-germline allocation trade-off hypothesis using quadratic models with relative badge size centered on the aviary (social group) mean. We did not include any interactions between badge size terms and body mass or tarsus length, because we had no clear predictions on the direction of such interactions and because our small sample sizes could have produced unreliable surface estimates resulting from interactions between continuous variables.

The dependent variables describing ejaculate quality were the proportion of motile sperm, initial swimming speed, sperm longevity and sperm swimming endurance. The dependent variables describing antioxidant use and oxidative stress in both sperm and red blood cells (RBCs) were the ratio of oxidized glutathione [GSSG/(GSSG + GSH), used as a measure of the oxidative stress endured by the cells], SOD activity, the proportion of SOD activity in the sperm relative to the total SOD activity in sperm and RBCs [SOD sperm/(SOD sperm+SOD $\mathrm{RBC}$ ), used as a measure of relative SOD investment into spermatic vs. somatic functions], MDA levels, and the proportion of MDA in the sperm relative to the total level of MDA in sperm and plasma [MDA sperm/(MDA sperm+MDA plasma), used as a measure of relative oxidative stress in the sperm vs. soma].

Proportions were either logit- or arcsine-transformed when necessary, while other dependent variables were log-transformed to match normality. All the models included the aviary and the sampling date as random factors and used restricted maximum likelihood method for parameter estimation. A KenwardRoger approximation was used for the computation of fixed effects degrees of freedom ( $\mathrm{R}$ package pbkrtest) (Halekoh and Højsgaard, 2014). The modeling was done using the package lme4 (Bates et al., 2015). To avoid inflating the type I error we did not apply model selection (Whittingham et al., 2006), and therefore always report results for full models. Further, we tested for collinearity between the model covariates using a variation inflation factor (VIF), using the $\mathrm{R}$ functions provided by Zuur et al. (2010). It is recommended that covariates having VIFs higher than 3 should be removed from the model due to their collinearity (reviewed by Zuur et al., 2010). In our analyses all the VIF values were below 1.3, and hence variance estimates of the model are unlikely to be biased by any collinearity between the covariates. All analyses were performed using R v. 3.1.1 (R Core Team, 2014).

\section{RESULTS}

\section{Badge Size and Social Dominance}

To estimate the dominance score for each aviary, we used an average of 82 dyadic interactions per aviary $(\min =31$ dyads, $\max =235$ dyads $)$. Neither total $\left[F_{(1,42.7)}=2.18, p=0.14\right]$ 
nor exposed $\left[F_{(1,42.4)}=2.51, p=0.12\right]$ relative badge size predicted the social rank. Interestingly, both models found that tarsus length was significantly positively correlated with social $\operatorname{rank}\left[5.81<F_{(1,54)}<5.85, p=0.019\right]$.

\section{Badge Size and Ejaculate Quality}

We did not find any correlations between any sperm performance trait, and either the total $(0.08<F<1.30, p>0.1$ for all covariates and models) or the exposed $(0.002<F<1.37$, $p>0.1$ for all covariates and models) badge size. Similarly, neither total $(0.009<F<1.45, p>0.1$ for all covariates and model $)$ nor exposed $(0.10<F<1.84, p>0.1$ for all covariates and model) relative badge size (within aviary) was related to any sperm performance trait. However, the models for sperm longevity showed a positive and significant correlation between body mass and sperm longevity $\left[5.70<F_{(1,50-51)}<6.42,0.014\right.$ $<p<0.021$ ), but this result is discussed elsewhere (Rojas Mora, 2016).

\section{Badge Size and Oxidative Stress}

We found a quadratic relation between levels of SOD in sperm and absolute total badge size $\left[F_{(1,44)}=4.30, p=0.044\right]$, although this relation was lost after removing an outlier $\left[F_{(1,46.4)}=0.43\right.$, $p=0.5$ ]. In both sperm and soma, the remaining markers of oxidative stress, antioxidant levels, or relative investment of antioxidants in sperm were neither correlated with the total $(0.0001<F<2.39, p>0.1)$ nor to the exposed $(0<F<2.38, p$ $>0.1$ ) absolute badge size.

We found a negative and significant correlation between the ratio of oxidized glutathione (GSSG) over total glutathione $(\mathrm{tGSH})$ in sperm and the total [Figure 1A; $F_{(1,40.3)}=4.36, p$ $=0.043$ ] and exposed [Figure 1B; $F_{(1,38)}=4.13, p=0.049$ ] badge size relative to the aviary mean. Further, we found that the total amount of GSSG was also negatively correlated with the total [Figure 1C; $F_{(1,40.6)}=3.66, p=0.063$ ] and the exposed [Figure 1D; $F_{(1,38)}=4.38, p=0.043$ ] relative badge size. Finally, in both sperm and soma we did not find any correlations between the remaining markers of oxidative stress, antioxidant levels, or relative investment of antioxidants in the sperm with the total $(0.004<F<2.85, p>0.1)$ or exposed $(0.0003<F<2.45$, $p>0.1)$ relative badge size.

\section{DISCUSSION}

In the present study we tested whether a melanin-based ornament could reflect male fertility (i.e., the phenotype-linked fertility hypothesis) and/or differential investment of antioxidant resources into the sperm vs. soma (i.e., the oxidation-based soma-germline allocation trade-off hypothesis) in male House Sparrows. We found that absolute badge size does not correlate with ejaculate quality. However, we found that males having relatively larger badges compared to other members of the same social group produced less oxidatively stressed sperm. Sperm redox status being an important component of male fertility (Aitken, 1999; Tremellen, 2008; Velando et al., 2008; Almbro et al., 2011) this result provides some support to the phenotypelinked fertility hypothesis, and females may accrue direct and indirect benefits in choosing males with relatively larger badges.

Our results do not support the hypothesis that male badge size may reflect how males strategically allocate antioxidant resources to their soma vs. their germline. This correlation would be expected if male ornaments correlated with their ability to monopolize fertile females, win at male-male interactions, and monopolize resources (e.g., dominance), an association suspected based on a meta-analysis conducted by Nakagawa et al. (2007), which showed that dominance is the only trait significantly correlated with badge size. Nonetheless, studies on the function of badge size often report contradictory results in House Sparrows (e.g., studies on extra-pair paternity and badge size: Cordero et al., 1999; Whitekiller et al., 2000; Václav et al., 2002). In our study, badge size and social dominance were unrelated, as previously found in other studies (Riters et al., 2004; Lindström et al., 2005). Thus, the latter result might explain the lack of association between ejaculate quality and relative badge size. However, this lack of association between badge size and dominance does not preclude badge size from being used by females in choosing their mates. Badge size is a conditiondependent trait that likely reflects phenotypic and genetic quality (Griffith et al., 1999), and it was suggested to be involved not only in male-male competition, but also in female mate choice (Hill and McGraw, 2006).

A recent meta-analysis found no correlation between male secondary sexual traits and ejaculate quality across various species (Mautz et al., 2013), and the authors argue that the direction of this relationship may depend on the mating system as well as on male ability to allocate resources into postvs. pre-copulatory traits (e.g., male condition, male ability to monopolize resources, etc.). For example, while studies in blackheaded grosbeaks Pheucticus melanocephalus (Hill, 1994) and green finches Carduelis chloris (Merilä and Sheldon, 1999) found an association between testis mass (e.g., a proxy for sperm production) and plumage ornamentation, other studies on house finches Carpodacus mexicanus (Rowe et al., 2012) and red-billed queleas Quelea quelea (Dale, 2000) failed to do so. Yet, those species vary in their levels of male territoriality and promiscuity. Further, it has been shown in jungle fowls Gallus gallus that while more dominant males with larger combs are better at protecting their soma from oxidative damage, only young males seem to be able to invest more resources to the antioxidant protection of their ejaculates (Noguera et al., 2012). Therefore, whether and how sexual ornaments signal sperm oxidative status and quality-the oxidation-based soma/germline allocation trade-off hypothesis-likely depends on the mating system (e.g., territorial vs. non-territorial, monogamous vs. lekking), which determines how males vary in their relative access to fertile females, and consequently the levels of sperm competition they face. Further, variation in mating systems can also determine individual life history strategies (e.g., current vs. future reproduction), which likely vary with age and environmental conditions.

Alternatively, it could be that badge coloration is a better predictor of sperm quality than badge size. For instance, it has been shown that plumage coloration correlates with ejaculate 


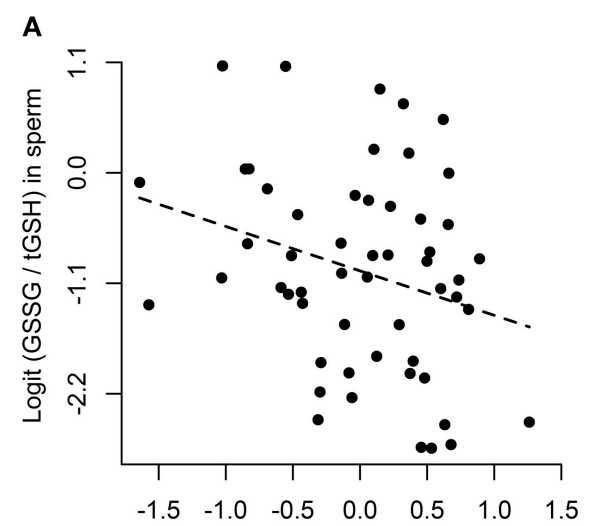

C

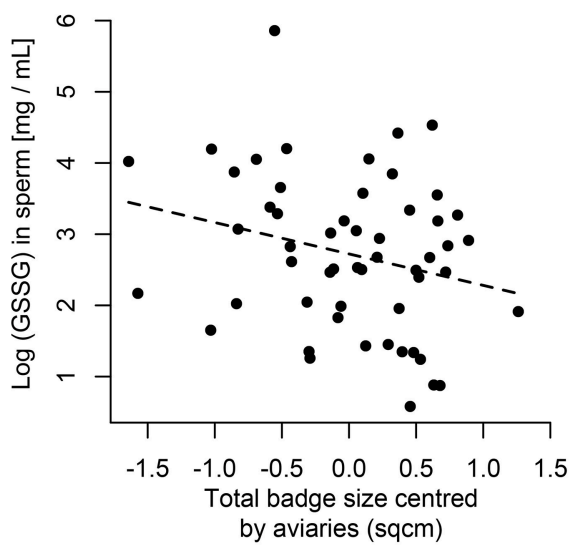

B

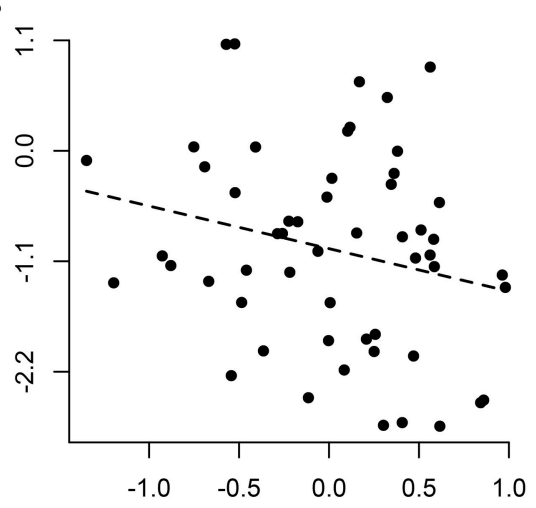

D

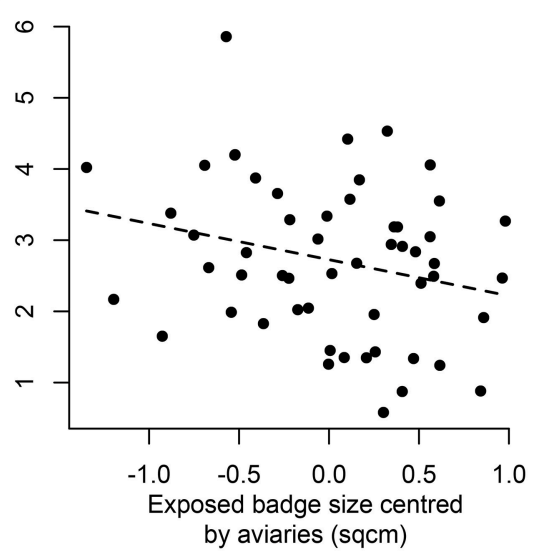

FIGURE 1 | Correlation between the levels of oxidative stress (GSSG/tGSH) in sperm and to the total (A) or exposed (B) badge size relative to the social group means. The lower panels show the correlation between the amount of oxidized glutathione (GSSG) and the total (C) or exposed (D) badge size relative to the social group means. The dashed lines represent a linear regression fit.

quality in great tits Parus major (Helfenstein et al., 2010) and in red-backed fairy wrens Malurus melanocephalus (Rowe et al., 2010). To what extent badge coloration varies across males in a given population, and whether females pay attention to these variations is unknown in house sparrows. In any case, and unfortunately, the way we took badge pictures, and in particular the lack of a white standard, precluded us from assessing plumage coloration, and whether badge coloration might advertise ejaculate quality to females remains to be tested in house sparrows.

Melanocortins bind to the G-protein-coupled melanocortin 1 receptor (MC1R) to produce darker colorations (Ducrest et al., 2008). However, melanocortins can also bind to other melanocortin receptors (MC2-5R) that have other functions than melanisation of tissues, and thus several traits are predicted to be pleiotropically affected by the production of more melanized ornaments (Ducrest et al., 2008). Further, the production of black ornaments has also been related to lower levels of glutathione, which antagonizes the production of eumelanin (Galván and Alonso-Alvarez, 2008, 2009). Hence, it has been proposed that individuals that have darker ornaments might be more resistant to stress, sexually more active, more aggressive, better at optimizing their energy balance, having better anti-inflammatory responses, and higher antioxidant capacities (Ducrest et al., 2008; Galván and Alonso-Alvarez, 2008, 2009). Such predictions have been observed in other taxa (reviewed by Ducrest et al., 2008), but to our knowledge we are the first to test whether males with larger melanin-based ornaments can better protect their ejaculates from oxidative stress. While we did not find any correlations between redox status in either soma or sperm and absolute badge sizes as predicted by the pleiotropic effects of the melanocortin system, we found that badge size relative to the social group is negatively related to the proportion of oxidized glutathione in the ejaculate (Figures 1A,B) as well as with the net levels of oxidized glutathione in the ejaculate (Figures 1C,D). Those results suggest that within a social group large-badged males have the potential to better protect their ejaculate from oxidative insults, and this is unrelated to their ability to monopolize resources (e.g., social dominance).

Altogether, we found that badge size relative to the social group reflects sperm redox status, and this is unrelated to social dominance, thus providing some support to the phenotypelinked fertility hypothesis. However, despite our fair sample sizes, our results are marginally significant and we cannot rule out typeI errors. Further, due to the molting patterns of house sparrows age could not be assessed. Noguera et al. (2012) reported that old 
male red jungle fowls invest less antioxidant in their semen than younger males, and how antioxidant allocation into sperm varies with age in the house sparrows is certainly worth investigating in the future Yet, it is to be noted that we assigned birds randomly to their aviaries and age classes should be randomly distributed across social groups. Consequently, age is unlikely to confound our results.

To conclude, we found that males having larger badges compared to other males in their social group produced less oxidatively stressed sperm. Given that sperm oxidative status is an important determinant of both male and female fertility, female house sparrows would accrue both direct and indirect fitness benefits in choosing to be fertilized by the more ornamented males within their social group.

\section{AUTHOR CONTRIBUTIONS}

$\mathrm{FH}$ and AR designed the study. AR and MM maintained the birds in the aviaries and collected the data. AR

\section{REFERENCES}

Agarwal, R., and Chase, S. D. (2002). Rapid, fluorimetric-liquid chromatographic determination of malondialdehyde in biological samples. J. Chromatogr. B 775, 121-126. doi: 10.1016/S1570-0232(02)00273-8

Aitken, R. J. (1999). The amoroso lecture the human spermatozoon - a cell in crisis? J. Reprod. Fertil. 115, 1-7.

Aitken, R. J., and Baker, M. A. (2004). Oxidative stress and male reproductive biology. Reproduct. Fertil. Dev. 16, 581-588. doi: 10.1071/RD03089

Almbro, M., Dowling, D. K., and Simmons, L. W. (2011). Effects of vitamin $\mathrm{E}$ and beta-carotene on sperm competitiveness. Ecol. Lett. 14, 891-895. doi: 10.1111/j.1461-0248.2011.01653.x

Alonso-Alvarez, C., Bertrand, S., Devevey, G., Prost, J., Faivre, B., and Sorci, G. (2004). Increased susceptibility to oxidative stress as a proximate cost of reproduction. Ecol. Lett. 7, 363-368. doi: 10.1111/j.1461-0248.2004. 00594.x

Bates, D., Mächler, M., Bolker, B., and Walker, S. (2015). Fitting linear mixedeffects models using lme4. J. Statist. Softw. 1, 1-51.

Benzie, I. F. F. (2000). Evolution of antioxidant defence mechanisms. Eur. J. Nutr. 39, 53-61. doi: 10.1007/s003940070030

Birkhead, T. R., Martínez, J. G., Burke, T., and Froman, D. P. (1999). Sperm mobility determines the outcome of sperm competition in the domestic fowl. Proc. R. Soc. B 266, 1759-1764. doi: 10.1098/rspb.1999. 0843

Birkhead, T. R., Veiga, J. P., and Fletcher, F. (1995). Sperm competition and unhatched eggs in the house sparrow. J. Avian Biol. 26, 343-345. doi: $10.2307 / 3677051$

Blount, J. D., Møller, A. P., and Houston, D. C. (2001). Antioxidants, showy males and sperm quality. Ecol. Lett. 4, 393-396. doi: 10.1046/j.14610248.2001.00255.x

Bouligand, J., Deroussent, A., Paci, A., Morizet, J., and Vassal, G. (2006). Liquid chromatography-tandem mass spectrometry assay of reduced and oxidized glutathione and main precursors in mice liver. J. Chromatogr. B 832, 67-74. doi: 10.1016/j.jchromb.2005.12.037

Cnubben, N. H. P., Rietjens, I. M. C. M., Wortelboer, H., Van Zanden, J., and Van Bladeren, P. J. (2001). The interplay of glutathione-related processes in antioxidant defense. Environ. Toxicol. Pharmacol. 10, 141-152. doi: 10.1016/S1382-6689(01)00077-1

Cohen, A. A., and McGraw, K. J. (2009). No simple measures for antioxidant status in birds: complexity in inter- and intraspecific correlations among circulating antioxidant types. Funct. Ecol. 23, 310-320. doi: 10.1111/j.13652435.2009.01540.x analyzed the sperm videos, measured the photos, conducted the laboratory analyses, and performed the statistical analyses. GG and AV provided analytical methods to quantify MDA and GSH/GSSG. AR and FH wrote the manuscript.

\section{ACKNOWLEDGMENTS}

We are thankful to the Laboratory of Behavioural Ecology at the university of Bern for providing all the facilities to accommodate the birds during the experiment. We thank Sabrina Ciprietti for her assistance in conducting the experiment. We are also grateful to all the farmers that allowed us to catch birds in their properties. This study was conducted thanks to a grant from the Swiss National Science Foundation n ${ }^{\circ}$ PP00P3_139011/1 to FH. Finally, we are grateful to the Veterinary Office of the Canton Bern (Switzerland) for providing us with the licenses $\mathrm{n}^{\circ}$ BE41/12 and WTH/g-525/14 for animal experimentation and detention.

Cordero, P. J., Wetton, J. H., and Parkin, D. T. (1999). Extra-pair paternity and male badge size in the house sparrow. J. Avian Biol. 30, 97-102. doi: $10.2307 / 3677248$

Cornwallis, C. K., and Birkhead, T. R. (2007). Changes in sperm quality and numbers in response to experimental manipulation of male social status and female attractiveness. Am. Natural. 170, 758-770. doi: 10.1086/521955

Costantini, D. (2008). Oxidative stress in ecology and evolution: lessons from avian studies. Ecol. Lett. 11, 1238-1251. doi: 10.1111/j.1461-0248.2008.01246.x

Dale, J. (2000). Ornamental plumage does not signal male quality in redbilled queleas. Proc. R. Soc. Lond. B Biol. Sci. 267, 2143-2149. doi: 10.1098/rspb.2000.1261

Denk, A. G., Holzmann, A., Peters, A., Vermeirssen, E. L. M., and Kempenaers, B. (2005). Paternity in mallards: effects of sperm quality and female sperm selection for inbreeding avoidance. Behav. Ecol. 16, 825-833. doi: 10.1093/beheco/ari065

Dowling, D. K., and Simmons, L. W. (2009). Reactive oxygen species as universal constraints in life-history evolution. Proc. R. Soc. B 276, 1737-1745. doi: $10.1098 / \mathrm{rspb} .2008 .1791$

Ducrest, A.-L., Keller, L., and Roulin, A. (2008). Pleiotropy in the melanocortin system, coloration and behavioural syndromes. Trends Ecol. Evol. 23, 502-510. doi: $10.1016 /$ j.tree.2008.06.001

Finkel, T., and Holbrook, N. J. (2000). Oxidants, oxidative stress and the biology of ageing. Nature 408, 239-247. doi: 10.1038/35041687

Froman, D. P., Feltmann, A. J., Rhoads, M. L., and Kirby, J. D. (1999). Sperm mobility: a primary determinant of fertility in the domestic Fowl (Gallus domesticus). Biol. Reprod. 61, 400-405. doi: 10.1095/biolreprod61.2.400

Froman, D. P., Pizzari, T., Feltmann, A. J., Castillo-Juarez, H., and Birkhead, T. R. (2002). Sperm mobility: mechanisms of fertilizing efficiency, genetic variation and phenotypic relationship with male status in the domestic fowl, Gallus gallus domesticus. Proc. R. Soc. B 269, 607-612. doi: 10.1098/rspb.2001.1925

Gage, M. J. G., Macfarlane, C. P., Yeates, S., Ward, R. G., Searle, J. B., and Parker, G. A. (2004). Spermatozoal traits and sperm competition in atlantic salmon: relative sperm velocity is the primary determinant of fertilization success. Curr. Biol. 14, 44. doi: 10.1016/s0960-9822(03)00939-4

Galván, I., and Alonso-Alvarez, C. (2008). An intracellular antioxidant determines the expression of a melanin-based signal in a bird. PLoS ONE 3:e3335. doi: 10.1371/journal.pone.0003335

Galván, I., and Alonso-Alvarez, C. (2009). The expression of melanin-based plumage is separately modulated by exogenous oxidative stress and a melanocortin. Proc. R. Soc. B 276, 3089-3097. doi: 10.1098/rspb.2009.0774

Gammell, M. P., De Vries, H., Jennings, D. J., Carlin, C. O. M., and Hayden, T. J. (2003). David's score: a more appropriate dominance ranking 
method than Clutton-Brock et al.'s index. Anim. Behav. 66, 601-605. doi: 10.1006/anbe. 2003.2226

Ginn, H. B., and Melville, D. S. (1983). Moult in birds. Br. Trust Ornithol.

Griffith, S. C., Owens, I. P. F., and Burke, T. (1999). Environmental determination of a sexually selected trait. Nature 400, 358-360. doi: 10.1038/22536

Halekoh, U., and Højsgaard, S. (2014). A kenward-roger approximation and parametric bootstrap methods for tests in linear mixed models - the R package pbkrtest. J. Stat. Softw. 1, 1-32. doi: 10.18637/jss.v059.i09

Halliwell, B., and Gutteridge, J. (2007). Free Radicals in Biology and Medicine. New York, NY: Oxford University Press, Inc.

Harman, D. (1956). Aging: A theory based on free-radical and radiation-chemistry. J. Gerontol. 11, 298-300. doi: 10.1093/geronj/11.3.298

Helfenstein, F., Losdat, S., Møller, A. P., Blount, J. D., and Richner, H. (2010). Sperm of colourful males are better protected against oxidative stress. Ecol. Lett. 13, 213-222. doi: 10.1111/j.1461-0248.2009.01419.x

Hill, G. E. (1994). Testis mass and subadult plumage in black-headed grosbeaks. Condor 96, 626-630. doi: 10.2307/1369465

Hill, G. E., and McGraw, K. J. (2006). Bird Coloration: Function and Evolution. Cambridge, MA: Harvard University Press.

Hõrak, P., and Cohen, A. (2010). How to measure oxidative stress in an ecological context: methodological and statistical issues. Funct. Ecol. 24, 960-970. doi: 10.1111/j.1365-2435.2010.01755.x

Jones, D. P. (2006). Redefining oxidative stress. Antioxid. Redox Signal. 8, 1865-1879. doi: 10.1089/ars.2006.8.1865

Keller, L., and Reeve, H. K. (1995). Why do females mate with multiple males? The sexually selected sperm hypothesis. Adv. Study Behav. 24, 291-316. doi: 10.1016/S0065-3454(08)60397-6

Lindström, K. M., Hasselquist, D., and Wikelski, M. (2005). House sparrows (Passer domesticus) adjust their social status position to their physiological costs. Horm. Behav. 48, 311-320. doi: 10.1016/j.yhbeh.2005.04.002

Malo, A. F., Garde, J. J., Soler, A. J., García, A. J., Gomendio, M., and Roldan, E. R. S. (2005). Male fertility in natural populations of red deer is determined by sperm velocity and the proportion of normal spermatozoa. Biol. Reprod. 72, 822-829. doi: 10.1095/biolreprod.104.036368

Mautz, B. S., Møller, A. P., and Jennions, M. D. (2013). Do male secondary sexual characters signal ejaculate quality? A meta-analysis. Biol. Rev. 88, 669-682. doi: $10.1111 /$ brv. 12022

McGraw, K. J. (2005). The antioxidant function of many animal pigments: are there consistent health benefits of sexually selected colourants? Anim. Behav. 69, 757-764. doi: 10.1016/j.anbehav.2004.06.022

Merilä, J., and Sheldon, C. B. (1999). Testis size variation in the greenfinch Carduelis chloris: relevance for some recent models of sexual selection. Behav. Ecol. Sociobiol. 45, 115-123.

Metcalfe, N. B., and Alonso-Alvarez, C. (2010). Oxidative stress as a lifehistory constraint: the role of reactive oxygen species in shaping phenotypes from conception to death. Funct. Ecol. 24, 984-996. doi: 10.1111/j.13652435.2010.01750.x

Møller, A. P. (1987). House sparrow, Passer domesticus, communal displays. Anim. Behav. 35, 203-210. doi: 10.1016/S0003-3472(87)80225-7

Møller, A. P. (1988). Badge size in the house sparrow Passer domesticus. Behav. Ecol. Sociobiol. 22, 373-378.

Møller, A. P. (1990). Sexual behavior is related to badge size in the house sparrow Passer domesticus. Behav. Ecol. Sociobiol. 27, 23-29. doi: 10.1007/BF00183309

Møller, A. P., and Birkhead, T. R. (1994). The evolution of plumage brightness in birds is related to extrapair paternity. Evolution 48, 1089-1100. doi: $10.2307 / 2410369$

Møller, A. P., and Erritzøe, J. (1992). Acquisition of breeding coloration depends on badge size in male house sparrows Passer domesticus. Behav. Ecol. Sociobiol. 31, 271-277.

Monaghan, P., Metcalfe, N. B., and Torres, R. (2009). Oxidative stress as a mediator of life history trade-offs: mechanisms, measurements and interpretation. Ecol. Lett. 12, 75-92. doi: 10.1111/j.1461-0248.2008.01258.x

Moselhy, H. F., Reid, R. G., Yousef, S., and Boyle, S. P. (2013). A specific, accurate, and sensitive measure of total plasma malondialdehyde by HPLC. J. Lipid Res. 54, 852-858. doi: 10.1194/jlr.D032698

Nakagawa, S., Ockendon, N., Gillespie, D. O. S., Hatchwell, B. J., and Burke, T. (2007). Assessing the function of house sparrows' bib size using a flexible meta-analysis method. Behav. Ecol. 18, 831-840. doi: 10.1093/beheco/arm050
Nakagawa, S., and Schielzeth, H. (2010). Repeatability for Gaussian and nonGaussian data: a practical guide for biologists. Biol. Rev. 85, 935-956. doi: 10.1111/j.1469-185x.2010.00141.x

Neff, B. D., Fu, P., and Gross, M. R. (2003). Sperm investment and alternative mating tactics in bluegill sunfish (Lepomis macrochirus). Behav. Ecol. 14, 634-641. doi: 10.1093/beheco/arg032

Noguera, J. C., Dean, R., Isaksson, C., Velando, A., and Pizzari, T. (2012). Agespecific oxidative status and the expression of pre- and postcopulatory sexually selected traits in male red junglefowl, Gallus gallus. Ecol. Evol. 2, 2155-2167. doi: 10.1002/ece3.300

Parker, G. A. (1970). Sperm competition and its evolutionary consequences in the insects. Biol. Rev. 45, 525-567. doi: 10.1111/j.1469-185X.1970.tb01176.x

Parker, G. A. (1998). "Sperm competition and the evolution of ejaculates: towards a theory base," in Sperm Competition and Sexual Selection, eds T. R. Birkhead and A. P. Møller (San Diego: Academic Press), 3-54.

Parker, G. A., Lessells, C. M., and Simmons, L. W. (2013). Sperm competition games: a general model for precopulatory male-male competition. Evolution 67, 95-109. doi: 10.1111/j.1558-5646.2012.01741.x

Parker, G. A., and Pizzari, T. (2010). Sperm competition and ejaculate economics. Biol. Rev. 85, 897-934. doi: 10.1111/j.1469-185x.2010.00140.x

Pike, T. W., Blount, J. D., Lindström, J., and Metcalfe, N. B. (2010). Dietary carotenoid availability, sexual signalling and functional fertility in sticklebacks. Biol. Lett. 6, 191-193. doi: 10.1098/rsbl.2009.0815

Pizzari, T., Cornwallis, C. K., and Froman, D. P. (2007). Social competitiveness associated with rapid fluctuations in sperm quality in male fowl. Proc. R. Soc. B 274, 853-860. doi: 10.1098/rspb.2006.0080

Pizzari, T., Dean, R., Pacey, A., Moore, H., and Bonsall, M. B. (2008). The evolutionary ecology of pre- and post-meiotic sperm senescence. Trends Ecol. Evol. 23, 131-140. doi: 10.1016/j.tree.2007.12.003

Preston, B. T., Stevenson, I. R., Pemberton, J. M., and Wilson, K. (2001). Dominant rams lose out by sperm depletion. Nature 409, 681-682. doi: 10.1038/35055617

R Core Team (2014). R: A Language and Environment for Statistical Computing, Vienna: R Foundation for Statistical Computing.

Reznick, D., Nunney, L., and Tessier, A. (2000). Big houses, big cars, superfleas and the costs of reproduction. Trends Ecol. Evol. 15, 421-425. doi: 10.1016/S01695347(00)01941-8

Riters, L. V., Teague, D. P., and Schroeder, M. B. (2004). Social status interacts with badge size and neuroendocrine physiology to influence sexual behavior in male house sparrows (Passer domesticus). Brain Behav. Evol. 63, 141-150. doi: $10.1159 / 000076240$

Rojas Mora, A. (2016). Oxidative Stress in Sperm Competition Games: Experimental Tests of the Soma vs. Germline Allocation Trade-Off in Wild House Sparrows Passer Domesticus. Ph.D in Biology, University of Neuchatel, Neuchâtel.

Rowe, M., Swaddle, J. P., Pruett-Jones, S., and Webster, M. S. (2010). Plumage coloration, ejaculate quality and reproductive phenotype in the redbacked fairy-wren. Anim. Behav. 79, 1239-1246. doi: 10.1016/j.anbehav.2010. 02.020

Rowe, M., Tourville, E. A., and McGraw, K. J. (2012). Carotenoids in bird testes: Links to body carotenoid supplies, plumage coloration, body mass and testes mass in house finches (Carpodacus mexicanus). Comp. Biochem. Physiol. B Biochem. Mol. Biol. 163, 285-291. doi: 10.1016/j.cbpb.2012.06.005

Rudolfsen, G., Figenschou, L., Folstad, I., Tveiten, H., and Figenschou, M. (2006). Rapid adjustments of sperm characteristics in relation to social status. Proc. $R$. Soc. B 273, 325-332. doi: 10.1098/rspb.2005.3305

Salmon, A. B., Richardson, A., and Pérez, V. I. (2010). Update on the oxidative stress theory of aging: does oxidative stress play a role in aging or healthy aging? Free Rad. Biol. Med. 48, 642-655. doi: 10.1016/j.freeradbiomed.2009. 12.015

Schneider, C. A., Rasband, W. S., and Eliceiri, K. W. (2012). NIH image to ImageJ: 25 years of image analysis. Nat. Methods 9, 671-675. doi: 10.1038/nmeth.2089

Sheldon, B. C. (1994). Male phenotype, fertility, and the pursuit of extrapair copulations by female birds. Proc. R. Soc. B 257, 25-30. doi: 10.1098/rspb.1994.0089

Siva-Jothy, M. T. (2000). The young sperm gambit. Ecol. Lett. 3, 172-174. doi: 10.1046/j.1461-0248.2000.00146.x

Sorci, G., and Faivre, B. (2009). Inflammation and oxidative stress in vertebrate host-parasite systems. Philos. Trans. R. Soc. B 364, 71-83. doi: $10.1098 /$ rstb.2008.0151 
Surai, P. F., Fujihara, N., Speake, B. K., Brillard, J.-P., and Wishart, G. J. (2001). Polyunsaturated fatty acids, lipid peroxidation and antioxidant protection in avian semen Asian-australas. J. Anim. Sci. 4, 1024-1050. doi: 10.5713/ajas.2001.1024

Tazzyman, S. J., Pizzari, T., Seymour, R. M., and Pomiankowski, A. (2009). The evolution of continuous variation in ejaculate expenditure strategy. Am. Nat. 174, E71-E82. doi: 10.1086/603612

Tremellen, K. (2008). Oxidative stress and male infertility - a clinical perspective. Hum. Reprod. Update 14, 243-258. doi: 10.1093/humupd/ dmn004

Václav, R., Hoi, H., and Blomqvist, D. (2002). Badge size, paternity assurance behaviours and paternity losses in male house sparrows. J. Avian Biol. 33, 315-318. doi: 10.1034/j.1600-048X.2002.330315.x

Velando, A., Torres, R., and Alonso-Alvarez, C. (2008). Avoiding bad genes: oxidatively damaged DNA in germ line and mate choice. Bioessays 30, 1212-1219. doi: 10.1002/bies.20838

Vladić, T. V., and Järvi, T. (2001). Sperm quality in the alternative reproductive tactics of Atlantic salmon: the importance of the loaded raffle mechanism. Proc. R. Soc. B 268, 2375-2381. doi: 10.1098/rspb.2001.1768

Von Schantz, T., Bensch, S., Grahn, M., Hasselquist, D., and Wittzell, H. (1999). Good genes, oxidative stress and condition-dependent sexual signals. Proc. $R$. Soc. B 266, 1-12. doi: 10.1098/rspb.1999.0597

Wang, Y., Salmon, A. B., and Harshman, L. G. (2001). A cost of reproduction: oxidative stress susceptibility is associated with increased egg production in Drosophila melanogaster. Exp. Gerontol. 36, 1349-1359. doi: 10.1016/S05315565(01)00095-X

Wetton, J. H., Burke, T., Parkin, D. T., and Cairns, E. (1995). Single-locus DNA fingerprinting reveals that male reproductive success increases with age through extra-pair paternity in the house sparrow (Passer domesticus). Proc. $R$. Soc. Lond. B 260, 91-98. doi: 10.1098/rspb.1995.0064
Wetton, J. H., and Parkin, D. T. (1991). An association between fertility and cuckoldry in the house sparrow, Passer domesticus. Proc. R. Soc. Lond. B 245, 227-233. doi: 10.1098/rspb.1991.0114

Whitekiller, R. R., Westneat, D. F., Schwagmeyer, P. L., and Mock, D. W. (2000). Badge size and extra-pair fertilizations in the House Sparrow. Condor 102, 342-348. doi: 10.1650/0010-5422(2000)102[0342:BSAEPF]2.0.CO;2

Whittingham, M. J., Stephens, P. A., Bradbury, R. B., and Freckleton, R. P. (2006). Why do we still use stepwise modelling in ecology and behaviour? J. Anim. Ecol. 75, 1182-1189. doi: 10.1111/j.1365-2656.2006.01141.x

Wilson-Leedy, J. G., and Ingermann, R. L. (2007). Development of a novel CASA system based on open source software for characterization of zebrafish sperm motility parameters. Theriogenology 67, 661-672. doi: 10.1016/j.theriogenology.2006.10.003

Yasui, Y. (1997). A "good-sperm" model can explain the evolution of costly multiple mating by females. Am. Natural. 149, 573-584. doi: 10.1086/286006

Zuur, A. F., Ieno, E. N., and Elphick, C. S. (2010). A protocol for data exploration to avoid common statistical problems. Methods Ecol. Evol. 1, 3-14. doi: 10.1111/j.2041-210X.2009.00001.x

Conflict of Interest Statement: The authors declare that the research was conducted in the absence of any commercial or financial relationships that could be construed as a potential conflict of interest.

Copyright $\odot 2016$ Rojas Mora, Meniri, Glauser, Vallat and Helfenstein. This is an open-access article distributed under the terms of the Creative Commons Attribution License (CC BY). The use, distribution or reproduction in other forums is permitted, provided the original author(s) or licensor are credited and that the original publication in this journal is cited, in accordance with accepted academic practice. No use, distribution or reproduction is permitted which does not comply with these terms. 